\title{
A CLASSE HOSPITALAR NA VOZ DE CRIANÇAS A PARTIR DE SUAS VIVÊNCIAS EDUCACIONAIS
}

- HILDACY SOARES DA FRANÇA MONTANHA

https:/ /orcid.org/0000-0002-2169-6831

Universidade Católica Dom Bosco

MARTA REGINA BROSTOLIN

https:/ /orcid.org/0000-0003-4262-2222

Universidade Católica Dom Bosco

RESUMO O presente artigo analisa experiências de crianças que frequentavam a Classe Hospitalar da Santa Casa de Misericórdia, na cidade de Campo Grande (MS). Ancorada na Sociologia da Infância, a pesquisa com abordagem qualitativa teve por objetivo analisar como as crianças da Classe Hospitalar vivenciam as suas experiências educacionais no período de internação. Os sujeitos foram cinco crianças, com idade entre cinco e doze anos. Como instrumento de coleta de dados, utilizou-se a entrevista semiestruturada e o desenho comentado. As experiências vivenciadas pelas crianças hospitalizadas que frequentam a classe hospitalar em questão são relevantes por nos possibilitar a compreensão de significados que têm para elas realizarem atividades pedagógicas fora do ambiente escolar inseridas nesse contexto de tratamento de doença. Os resultados evidenciaram que a Classe Hospitalar atua na perspectiva de manter as crianças conectadas com o universo escolar que deixaram ao serem internadas. A sensibilidade e a afetividade docente resultam no fortalecimento para superar os dias de internação hospitalar.

Palavras-chave: Criança. Classe Hospitalar. Vivências educacionais.

\section{ABSTRACT THE HOSPITAL CLASSROOM IN THE VOICE OF}

\section{CHILDREN FROM THEIR EDUCATIONAL EXPERIENCE}

This article examines the experiences of children attending with hospitalized children who attended the Santa Casa de Misericórdia hospital school class in the city of Campo Grande - MS. Set on Sociology of Childhood, this qualitative data research aimed to analyze how children in Hospital Classes undergo through educational experience during hospitalization period. The subject were five children 
aging between five to twelve years old. The semi-structured interview and the commented drawing were used as a data collection instrument. The experiences lived by the hospitalized children who attend the hospital school class are relevant because they enable us to understand what it means for them to carry out pedagogical activities not only outside the school environment but also inserted in this disease treatment context. The results evidenced that the hospital school class acts upon keeping the children connected with the school universe that they left when they were hospitalized. The sensitivity and affection of the teacher result in the children's' strengthening to overcome the days of hospitalization.

Keywords: Child. Hospital Class. Educational experience.

\section{RESUMEN LA CLASE HOSPITALAR EN LA VOZ DE LOS NIÑOS DESDE SU EXPERIENCIA EDUCATIVA}

Este artículo analisa experiencias de niños hospitalizados, que asistían a la clase hospitalaria en la Santa Casa de Misericórdia, en la ciudad de Campo Grande - MS. Apoyada en Sociología de la Infancia, la investigación con un enfoque cualitativo pretende analizar cómo los niños experimentan las prácticas educativas durante el período de hospitalización en la clase de hospital. Los sujetos encuestados fueron cinco niños, con edades entre cinco y doce años. Como instrumento de recogida de datos, se utilizaron entrevistas semiestructuradas y diseño comentado. Las experiencias vividas por los niños hospitalizados que asisten a la clase de hospital son relevantes porque nos permiten comprender qué significados tienen para que lleven a cabo actividades educativas fuera del entorno escolar y se inserten en este contexto de tratamento de enfermedades. Los resultados mostraron que la classe hospitalaria funciona con la perspectiva de mantener a los niños conectados con el universo escolar que dejaron cuando fueron hospitalizados. La sensibilidad y el afecto del maestro se traducen en un fortalecimiento para superar los días de hospitalización.

Palabras Clave: Niño. Clase hospitalaria. Experiencia educativa.

\section{Introdução}

Este texto apresenta recortes de uma pesquisa de mestrado realizada com crianças que frequentavam a Classe Hospitalar no Hospital Santa Casa de Misericórdia na cidade de Campo Grande (MS). Teve por objetivo analisar como as crianças da Classe Hospitalar vivenciam suas experiências educacionais no período de internação. A pesquisa se fundamentou teoricamente no campo da Sociologia da Infância, apoiada em estudos de pesquisadores 
como Sarmento (2013), Corsaro (2011), Soares $(2005,2015)$, dentre outros, que contribuiram para a compreensão da importância em escutar as crianças.

A metodologia de cunho qualitativo adotou a observação direta por se tratar de pesquisa com crianças e da necessidade de manter-se próximo aos sujeitos e ao contexto da investigação. Por se tratar de uma pesquisa com criança há um cuidado ético maior em respeito às diversas formas de expressão da criança, bem como o fato de estar em um ambiente hospitalar em que as emoções são mais intensas como chorar, sentir dor, saudade e medo, o que torna a relação de confiança entre a criança e o pesquisador fundamental exigindo muita sensibilidade. Portanto, a observação direta possibilitou essa relação de respeito, além de permitir ao pesquisador compreender os significados que os sujeitos atribuem à realidade em que estão inseridos (LÜDKE; ANDRÉ, 2014).

Além da observação direta, foram utilizados para a coleta de dados a entrevista semiestruturada e o desenho comentado que possibilitaram o acesso e posterior análise das narrativas das crianças sobre suas experiências educacionais na Classe Hospitalar. Os dados foram coletados no período de abril a julho de 2019. Foram sujeitos da pesquisa cinco crianças com idade entre cinco e doze anos, embora, neste artigo, por ser um recorte da pesquisa, apresentamos as narrativas de duas crianças. Para a realização das entrevistas, adotou-se como recurso um brinquedo-personagem inspirado no trabalho de Rocha (2012). Os bonecos de heróis escolhidos para apresentar as crianças foram o Homem Aranha, Capitão América, Homem Formiga e Mulher-Maravilha.

Optamos por personagens de super heróis por despertar nas crianças a esperança, a imaginação, por se tratar de personagens que podem obter qualquer poder que the for sugerido, segundo a criatividade de cada um.
Após apresentar os heróis, iniciamos o diálogo remetendo aos desenhos animados que as crianças demonstravam interesse. Usamos os bonecos heróis para contar uma história na qual, resumidamente, relatava que os heróis estavam em missão de conhecer a rotina do hospital e que deveriam encontrar uma criança para auxiliá-los. Essa criança poderia depois da missão cumprida compor um novo herói com os poderes que ela considerasse necessários. Esse recurso nos permitiu trabalhar com o roteiro proposto para as entrevistas. A escolha do brinquedo-personagem também necessitou respeitar os padrões de assepsia solicitada pela equipe da Classe Hospitalar, que, por sua vez, se adequa às determinações do Setor de Controle de Infecção Hospitalar.

O presente texto está organizado em três momentos: o primeiro apresenta um breve histórico da concepção de criança e infância e os direitos da criança a partir dos preceitos da Sociologia da Infância. O segundo aborda o contexto da Classe Hospitalar, as leis que a amparam e a dinâmica de seu funcionamento, e o último apresenta fragmentos das vivências educacionais narradas por duas crianças e as reflexões provocadas pela análise.

\section{Sociologia da Infância: a criança e seus direitos}

Pesquisadores têm contribuído nas últimas décadas por meio de suas produções científicas sobre a infância em direcionar um novo olhar para a pesquisa a partir da criança, trazendo-a como protagonista (FARIA, DEMERTINI, PRADO, 2005). Esses estudos revelaram períodos na história em que a criança era invisível socialmente, embora pertencente à instituição familiar, as crianças não eram reconhecidas em suas singularidades.

Segundo Ariès (1981), a criança era vista como uma projeção do adulto em escala, isto 
é, não havia distinção entre o mundo adulto e o infantil, as crianças viviam em meio ao universo dos adultos. Os estudos desse autor foram realizados pela iconografia, fundamentados em análises de obras de artes produzidas ao longo da história, destacando que, durante parte da Idade Média, as crianças eram consideradas como meros seres biológicos, sem estatuto social e autonomia. Abramowicz e Moruzzi (2016) reconhecem no trabalho de Ariès (1981) pontos pertinentes para impulsionar a concepção de infância que temos hoje.

A ideia de emergência é importante, pois não designa uma origem, mas emergir significa que há um determinado momento em que se 'dá a ver', em que se visibiliza e também se enuncia a criança a partir de diversas forças, entre elas: econômicas, sociais, estéticas, literárias, médicas, sanitárias, pedagógicas etc, que fizeram emergir a partir do século XVIII esta forma, que é vazia no sentido de sem essência, denominada criança. (ABRAMOWICZ; MORUZZI, 2016, p. 26)

Crianças sempre existiram independentemente das concepções que se tinham delas, e embora os estudos de Ariès tenham uma grande contribuição, há críticas a sua abordagem. Kuhlmann e Fernandes (2012) consideraram a abordagem de Ariés um recorte social e temporal de uma realidade específica, fato que não abrange todas as classes, apontando que sua análise não considerou todas as obras de arte que incluíam representações de crianças. A crítica que se faz é que não se pode simplificar as mudanças ocorridas na inexistência à existência do sentimento de infância, pois necessita levar em conta as tensões existentes em torno das relações sociais que constituem os processos históricos.

A infância em suas atribuições sociais sofre variações segundo os momentos históricos e as diferentes concepções de sociedades e culturas. Compreende-se pelos estudos desenvolvidos nessa área que não há uma infância universal, há sim muitas infâncias pelo mundo, que se diferenciam nas especificidades, ainda que possam ser semelhantes em suas características biológicas, ainda assim, não é suficiente para neutralizar as diferenças históricas, culturais e sociais (BELLONI, 2009).

Reconhecer a dinamicidade, as mudanças que ocorrem na sociedade, fez com que a Sociologia da Infância ampliasse seu olhar e levou-a a legitimar a criança e a infância como um fenômeno social e assim ampliar a pesquisa nesse espaço. Para compreender o processo de constituição da disciplina científica voltamos as primeiras décadas do século XX. Em 1920, nos Estados Unidos, cinco sociólogos americanos começaram a estudar a temática: William I. Thomas, Dorothy S. Thomas, Stanley P. Davies, E. W. Brugess e Kimmball Young (ABRAMOWICZ; OLIVEIRA, 2010). Na França, Marcel Mauss apresentou uma comunicação sobre a Sociologia da Infância em um congresso ocorrido em 1937 e, em 1947, no Brasil, destacase o trabalho pioneiro de Florestan Fernandes sobre as Trocinhas do Bom Retiro (ABRAMOWICZ; OLIVEIRA, 2010).

Esse anseio da Sociologia da Infância originou-se devido a outras áreas como a psicologia, a medicina, a própria pedagogia não focarem a criança em seu estatuto social, e sim buscavam compreender o desenvolvimento e comportamento das crianças, geralmente dentro das instituições educativas ou familiares.

Ainda que sejam contribuições relevantes, esses estudos estão centrados em esclarecer questões segundo o olhar dos adultos, "é comum que os adultos vejam as crianças de forma prospectiva, isto é, em uma perspectiva do que se tornarão - futuros adultos, com um lugar na ordem social e as contribuições que a ela darão" (CORSARO, 2011, p. 18). A ideia equivocada de que a criança é um inativo social, um ser passivo, um devir, não pode ser levada adiante, pois a “infância é um fenômeno social, um componente estrutural e cultural 
específicos de muitas sociedades" (BELLONI, 2009, p.130). É da Sociologia da Infância que emerge a intencionalidade em conceber, por meio de conhecimentos produzidos pela pesquisa, esse fenômeno social criança como ser biopsicossocial e o fenômeno social infância como categoria geracional na estrutura da sociedade (SARMENTO, 2013).

Embora esteja presente nos discursos das políticas públicas, estudos e pesquisas, essa intencionalidade acerca da infância e a compreensão das crianças como sujeitos de direitos, nas mais variadas áreas do saber e na sociedade como um todo, continuam sendo uma realidade não concreta. Segundo Soares (2005), a incumbência de atribuir direitos à criança tem tido um longo e tortuoso caminho, dificuldades que ocorrem devido à lenta conscientização da sociedade que não compreende a necessidade das crianças, bem como a cultura enraizada em diversos períodos históricos.

Destaca-se como marco na conquista dos direitos da criança um evento internacional nomeado o Ano Internacional da Criança (AIC), com promulgação oficialmente assinada no ano de 1979, pelo secretário-geral das Nações Unidas, o qual elucida as questões dos diretos das crianças. 0 objetivo do evento foi chamar a atenção para problemas sofridos pelas crianças em todo o mundo, como a desnutrição, saneamento básico e a falta de acesso à educação.

O movimento AIC deu origem a Convenção Internacional dos Direitos da Infância que é o tratado sobre os Direitos Humanos mais ratificado na história, a partir de um grupo de trabalho estabelecido pela Comissão de Direitos Humanos da Organização das Nações Unidas (ONU). Suas diretrizes estão contidas na Declaração Internacional dos Direitos da Criança, aprovada em 20 de novembro de 1989. A Convenção foi adotada por 196 países e o Brasil ratificou a Convenção sobre os Direitos da Criança em 24 de setembro de 1990, ano também de criação do Estatuto da Criança e do Adolescente (ECA).

\section{A Classe Hospitalar e seu contexto}

Historicamente, remonta as primeiras décadas do século XX na Europa algumas atividades educativas oferecidas às crianças, marcando o início do que consideramos atualmente como Classe Hospitalar (OLIVEIRA, 2013).

Os primeiros atendimentos escolares hospitalares ocorreram na França, no ano de 1929, na associação em defesa da escolarização de crianças e adolescentes doentes, denominada Association L'École à l'Hôpital, fundada pela professora de Filosofia Louise (RIBEIRO, 2013). Posteriormente, mais precisamente, no ano de 1935, iniciaram em Paris, as atividades designadas à Classe Hospitalar, implantada por Henri Sellier, na intenção de incentivar as crianças e adolescentes vítimas da guerra a dar continuidade no desenvolvimento escolar (PACCO, 2017).

A partir de estudos originados da observação e interesse às necessidades das crianças, houve o aprimoramento da Classe Hospitalar, que por meio das políticas públicas pôde dar atenção à problemática da saúde de crianças em idade escolar que necessitavam de hospitalização por longo tempo (OLIVEIRA, 2013). A formação do professor para atuar em hospitais teve destaque em 1939, ano em que foi criado, segundo Oliveira (2013), pelo Ministério da Educação da França, o cargo de professor hospitalar e o Centro Nacional de Estudos e de Formação para a Infância Inadaptada (CNEFEI) na comuna de Suresnes, em Paris. Tinha a finalidade de formar docentes para atuar nas instituições que ofereciam para crianças o atendimento educacional especial e também em hospitais. 
Anos mais tarde, já na década de 1980, foi estabelecida a Associação para a melhoria das condições de hospitalização das crianças, a Associação para a Melhoria de Condições das Crianças (Apache), que era vinculada a Associação Européia para Criança em Hospital (EACH), organização que reúne outras associações em defesa dos direitos das crianças e adolescentes hospitalizados (GEREMIAS, 2010).

No Brasil, o atendimento na Classe Hospitalar inicia-se em agosto de 1950, no Hospital Municipal Bom Jesus, um hospital público infantil, localizado no Rio de Janeiro. Foi um trabalho realizado pela professora Lecy Rittmeyer visando criar a primeira Classe Hospitalar, com a intenção de auxiliar as crianças internadas em suas necessidades escolares diminuindo possiveis problemas com seu retorno às escolas regulares (GEREMIAS, 2010). No entanto, alguns estudos evidenciam que esse atendimento remonta ainda no Brasil Colônia, na Santa Casa de Misericórdia de São Paulo, por volta do ano de 1600 (GEREMIAS, 2010).

Para Barros (2011), a origem da possivel Classe Hospitalar no Brasil está intimamente vinculada à origem do ensino especial do nosso país, no qual os asilos para alienados ajudam a compreender o pertencimento ao qual a escolarização em hospitais se enquadrou.

Atualmente, a Classe Hospitalar é um serviço destinado a prover mediante atendimento especializado, o atendimento educacional para crianças e adolescentes impedidos de frequentar a escola por razões de tratamento de saúde (BRASIL, 2002). É um direito das crianças e adolescentes brasileiros assegurados por lei, embora, ainda hoje, os esforços políticos pela implantação de Classes Hospitalares em alguns estados sejam insatisfatórios (LIMA, 2015). O objetivo desse atendimento pedagógico hospitalar consiste em dar continuidade ao processo de escolarização, amenizando os problemas de evasão escolar e possibilitando um retorno adequado à escola regular.

Apesar da escolarização ter um reconhecimento formal, regulamentado na Constituição Federal de 1988, nos artigos 225 e 227, os quais direcionam a responsabilidade da família, da sociedade e do Estado em garantir a seguridade a saúde e a educação das crianças, ainda se faz necessário aparatos legais específicos para garantir a educação de grupos minoritários ou menos favorecidos, assim como para as crianças e adolescentes que necessitam se ausentar da escola para tratamento de saúde.

A legislação brasileira reconhece o acompanhamento educacional de crianças e adolescentes hospitalizados por meio da Política Nacional de Educação Especial desde o ano de 1994 (MEC/SEESP, 1994), e propõe que a educação em hospital deve ser realizada através da organização de Classes Hospitalares, devendo-se assegurar o acompanhamento educacional não só das crianças e adolescentes com transtornos do desenvolvimento, mas, também àqueles em situação de risco, como é o caso da internação hospitalar (PAULA, 2007).

Esse atendimento ganhou força quando o Conselho Nacional dos Direitos da Criança e do Adolescente (Conanda), que é autoridade nacional na rede de proteção e aplicação do ECA, editou a Resolução de no 41 de 13 de outubro de 1995 (BRASIL, 1995), com apoio da Sociedade Brasileira de Pediatria (SBP), garantindo a escolarização dos estudantes em hospitais. 0 texto apresenta 20 pontos, por meio dos quais são descritas as ações a serem reconhecidas como Direitos da Criança Hospitalizada.

A Lei no 9.394/96, que estabelece as Diretrizes e Bases da Educação Nacional (LDBEN), traz a Classe Hospitalar como atendimento da educação especial. Em seu artigo 58, define educação especial como sendo “[...] a modalidade de educação escolar, oferecida preferencialmente na rede regular de ensino, para educandos 
portadores de necessidades especiais". Descreve ainda no inciso $2^{\circ}$ desse mesmo artigo que " $O$ atendimento educacional será feito em classes, escolas ou serviços especializados, sempre que, em função das condições específicas dos alunos, não for possivel a sua integração nas classes comuns do ensino regular".

Posteriormente, a Lei no 9.394/96 sofreu uma alteração para assegurar atendimento educacional ao aluno da educação básica internado para tratamento de saúde em regime hospitalar ou domiciliar por tempo prolongado. Passou, então, a vigorar acrescida do seguinte artigo:

Art. 40-A. É assegurado atendimento educacional durante o período de internação, ao aluno da educação básica internado para tratamento de saúde em regime hospitalar ou domiciliar por tempo prolongado, conforme dispuser o Poder Público em regulamento, na esfera de sua competência federativa.

O Ministério da Educação (MEC), por meio da Secretaria de Educação Especial, editou, em 2002, um documento denominado Classe hospitalar e atendimento pedagógico domiciliar: estratégias e orientações, não é uma lei, mas um guia de estratégias e orientações com o objetivo de organizar ações políticas para a estruturação do sistema de atendimento pedagógico e educacional em ambientes hospitalares e domiciliares. Especifica em seu Artigo $13^{\circ}$ :

Os sistemas de ensino, mediante ação integrada com os sistemas de saúde, devem organizar o atendimento educacional especializado a alunos impossibilitados de frequentar as aulas em razão de tratamento de saúde que implique internação hospitalar, atendimento ambulatorial ou permanência prolongada em domicílio. (BRASIL, 2002, p. 3)

A terminologia para o atendimento educacional em hospitais "Classe Hospitalar" é citada claramente nesse documento, sendo denominada como o atendimento pedagógi- co-educacional que ocorre em ambientes de tratamento de saúde, seja na circunstância de internação, como tradicionalmente conhecida, seja na circunstância do atendimento em hospital-dia e hospital-semana ou em serviços de atenção integral à saúde mental (BRASIL, 2002).

Além disso, o documento atenta para a humanização das relações nesse contexto, no sentido de aproximar essa temática da sociedade. Temática essa extremamente necessária, pois embora venha aumentando o número de pesquisadores interessados, os educadores, a sociedade em geral desconhecem, muitas vezes, que o hospital necessite de um espaço educativo para atender as crianças e adolescentes em idade escolar. Esse atendimento não deve se restringir apenas no desenvolvimento educacional, mas também tenha uma assistência motivadora, que auxilie nas questões relacionadas à mudança de rotina, à ausência da família, ao sofrimento dos procedimentos que causam dor, bem como o retorno à escola de origem.

\section{A Classe Hospitalar e seus protagonistas: as crianças}

Viver dias da infância em um hospital possibilita sentir todos os sentimentos que fora dele talvez fosse necessário uma vida toda para senti-los. O contado com a doença, a possibilidade de morte, de coma, de alta, de cura, de gravidade da doença, de dor, da ausência dela, de alegrias, de tristeza, de amor, de solidariedade, de saudade, de espanto, de medo, de curiosidade, de vergonha, de surpresa, a angústia do barulho e do silêncio, são manifestações vividas em um só dia na Classe Hospitalar.

A inserção no campo da pesquisa mostrou que se tratava de um ambiente muito delicado, cheio de detalhes que não podem ser deixados de lado. "Cada caso é um caso" ditado 
simples, mas que no ambiente de uma classe hospitalar tem um grande significado. Essa frase foi dita várias vezes pelos professores em meio às conversas durante as observações. Sensibilidade é um pré-requisito imprescindível em um profissional frente às crianças que frequentam a Classe Hospitalar.

A brinquedoteca é o lugar central da Classe Hospitalar, como ponto de apoio, acolhida, lugar de encontros, o porto seguro. Nesse ambiente, as crianças recebem atenção, brincam, fazem novas amizades, as mães conversam com outras mães. O professor responsável pela brinquedoteca conversa, oferece desenhos, atividades lúdicas, como por exemplo, o faz de conta, jogos pedagógicos e está sempre se movimentando, conversando com todos ao mesmo tempo, aparentemente responsável por um clima mais alegre e voltado única e exclusivamente para as crianças e seus acompanhantes.

A brinquedoteca atua como um refúgio dos momentos desconfortáveis vividos na rotina de internação. As crianças sorriem muito, nem parecem que estão doentes, se não fosse pelas roupas, curativos e procedimentos constantes e necessários dos profissionais de saúde. Seus olhares são brilhantes, suas vozes alcançam o mais alto volume, as mães parecem descansar nesse ambiente, pois, além do leito, esse é o único espaço mais acolhedor para seus filhos.

A brinquedoteca representa um ambiente que favorece o desenvolvimento das crianças em suas infâncias, ainda que estejam hospitalizadas, torna-se o cantinho da alegria durante esse período de tanta complexidade. A instalação de brinquedoteca em hospitais está prevista pela Lei no 11.104/2005 tanto para hospitais públicos como hospitais privados de todo Brasil, desde que tenha unidade pediátrica, sua implantação tornou-se obrigatória a partir dos movimentos de humanização nos hospitais. Essa conquista da inclusão do brinquedo no ambiente hospitalar vem sendo reconhecida como parte do tratamento, acontecendo assim, o reconhecimento das necessidades das crianças e da importância da brincadeira para promoção do bem-estar físico, emocional e social durante o tratamento de saúde (PAULA, 2007).

As cinco crianças, protagonistas da pesquisa, tinham de cinco a doze anos de idade. Três crianças com seis anos, uma com sete anos e uma com doze anos de idade. Tratava-se de três crianças do 10 ano, uma do 3 으 e uma do $6 \underline{0}$ ano do ensino fundamental. Todas de escolas públicas, sendo três do interior do estado de Mato Grosso do Sul e duas da capital. O que levou as crianças a estarem hospitalizadas foram queimaduras de pele, pneumonia, trombose séptica, artrite séptica. Todas apresentando gravidade sobre essas patologias que as levaram a um período maior que 30 dias de internação.

As crianças participantes da pesquisa são identificadas por nomes fictícios escolhidos por elas mesmas. De acordo com Leite (2008), a identificação dos nomes de crianças em pesquisas é um elemento delicado e que requer muita cautela, pois se estima a visibilidade e seu protagonismo, porém, deve-se sempre respeitar as questões éticas, mantendo suas identidades preservadas.

\section{Fragmentos de vivências na Classe Hospitalar pela voz das crianças}

A qualquer momento da vida, estamos expostos a doenças. Porém, considera-se pouco essa possibilidade até o dia em que ela acontece. "Adoecer em qualquer idade, implica sofrimentos físicos e emocionais, dificilmente aceitos na fase da infância e adolescência" (ROCHA, 2012, p.104). A hospitalização priva a criança de interações com seus grupos de convívio, a criança fica fragilizada, despida de seus objetos pessoais, distante dos familiares 
e amigos, dos colegas da escola e de seus professores, privada da comida caseira, dos brinquedos prediletos, entre outras coisas, é um grande impacto, que pode se configurar como uma agressão na vida da criança se não for bem conduzida.

A palavra "vivência", elemento chave, potente na pesquisa e no texto, significa aquilo que viveu; experienciar situações; os conhecimentos adquiridos ao viver ou até mesmo os hábitos de vida próprios de alguém (NEVES, 2009). Essas vivências são retratadas nesta seção a partir de narrativas e desenho de duas das cinco crianças sujeitos da pesquisa sobre suas experiências educacionais e os significados atribuídos por elas.

Figura 1 - Minecraft

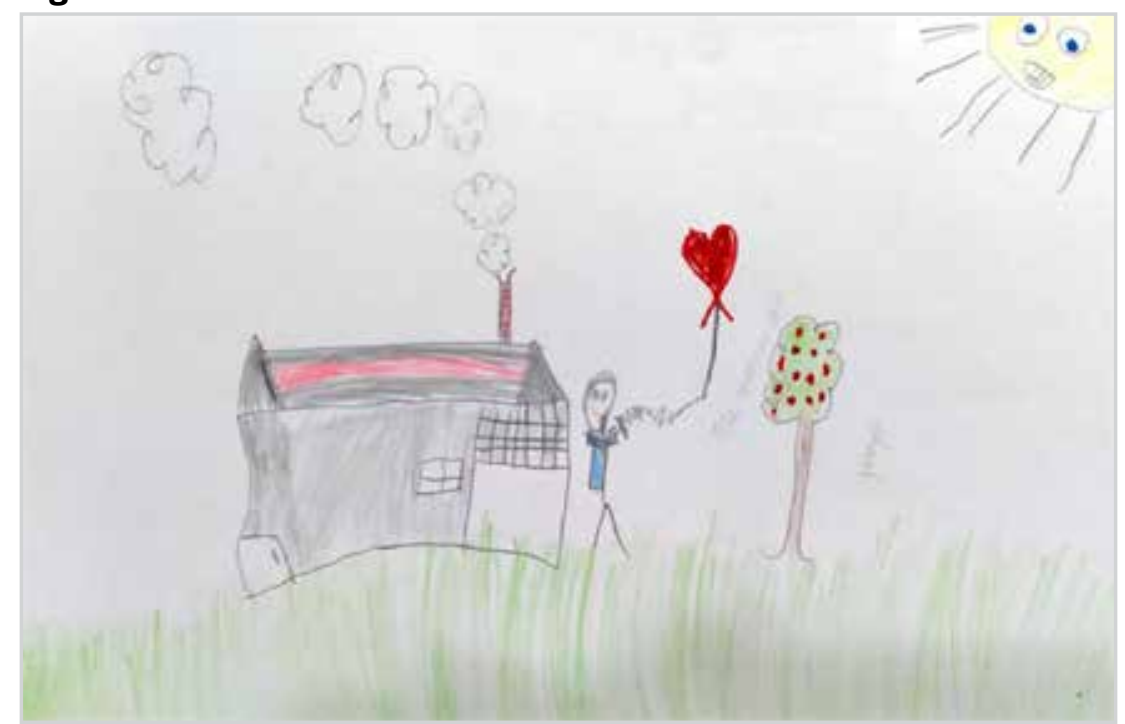

Fonte: construído por Minecraft.

Minecraft, um menino de seis anos, está no 1o ano do ensino fundamental. É um menino comunicativo, ao longo das nossas conversas, foi se soltando, demostrando gostar muito de conversar e falar sobre seus jogos de videogame. Surge do gostar de jogos, o nome fictício "Minecraft", sendo esse o jogo de videogame que ele mais gosta. Ele mora no interior do estado, na cidade de São Gabriel do Oeste. Em Campo Grande, na ala pediátrica, estava internado há 41 dias, sempre acompanhado pela mãe.

Quando questionado como se sentia estando há mais de 40 dias no hospital, Minecraft respondeu: "Eu sinto saudade da minha cachorrinha. Ela tem ciúmes de mim desde pequena. Quando eu nasci, ela já estava na minha casa, ela é mais velha do que eu".

Nesse momento, Minecraft muda seu olhar, seu pensamento se volta para sua casa e ele começa a relatar várias histórias que viveu com sua cachorrinha e com os animais de estimação de sua avó. As histórias eram engraçadas e rimos muito. Trugilho (2003), ao fazer referência ao humor nesse contexto, destaca que ele emerge como virtude que possibilita ao homem enfrentar, suportar e transcender a situação de tragicidade buscando por meio do humor minimizar o sofrimento que esse período proporciona.

Enquanto mostrava suas construções de casas e castelos no jogo de Minecraft no celular, relatou que quando crescesse queria ser engenheiro civil, pois já leva muito jeito com obras e construções. Nesse momento, foi perguntado sobre o encontro com professores no hospital, como ele se sentiu diante desse fato?

Minecraft: Eu já sabia, porque eu tive professor lá no hospital da minha cidade. Ela me dava 
atividade pra fazer lá. Os professores daqui são todos bonzinhos.

Pesquisadora: E como são os professores na sua escola?

Minecraft: ah, lá são mais esquentados, têm muitas crianças para cuidar.

Notamos que o trabalho da Classe Hospitalar se estende aos hospitais do interior do estado. Evidencia também que o atendimento pedagógico hospitalar proporciona aos professores um suporte e um tempo de atenção diferenciado das escolas regulares, justificado por Minecraft, devido ao número de alunos por professor. Uma realidade já conhecida das escolas brasileiras - a superlotação das salas de aula das escolas públicas. O que chamou a atenção foi a observação vinda da criança, ela não fala mal dos seus professores da escola regular, Minecraft argumenta de uma forma muito segura compreender que o excesso de crianças dificulta o trabalho do professor.

É importante considerar e escutar a criança como sujeito de direito, sendo capaz de manifestar suas opiniões diante das questões sociais, políticas e econômicas. Minecraft demostrou com sua justificativa que as crianças observam e são capazes de levantar ideias e ter conclusões sobre os assuntos que lhes dizem respeito. No entanto, é fundamental promover e garantir a conquista da participação efetiva das crianças, que, por muitas vezes, acontece somente no plano teórico. Essa participação é vista pelos adultos como um grande desafio, pois há a concepção de perda de controle sobre a criança, mas não se trata disso, constituise de uma negociação e de relações mais horizontais entre adultos e crianças (TOMÁS, 2007).

Em meio à conversa, perguntamos em qual local realizava as atividades escolares, se no leito ou na sala da brinquedoteca? Minecraft olhou para sua mãe, com esse gesto pedindo ajuda na resposta, a mãe em sintonia respon- deu pelo filho, explicando que, nos primeiros dias, ele ia até a brinquedoteca e realizava as atividades na sala reservada para as aulas individuais e, após a aula, brincava com os brinquedos da brinquedoteca, mas depois das cirurgias, devido ao acesso venoso, , ficou mais dificil de frequentar esse espaço e desde então, as atividades têm sido realizadas no leito. Durante o relato da mãe, Minecraft interfere e fala: "Eu gostava muito de ir lá (brinquedoteca), mas agora não dá mais. Ainda bem que agora eu tenho o videogame, que aqui já tá dando briga!".

Ao dizer isso, Minecraft sorri e olha para sua mãe que também sorri. Explicam que os dois disputam nos jogos. Observamos que há uma relação de grande parceria entre mãe e filho, a internação é para o tratamento do filho adoentado, mas a mãe também sente todo esse processo, sofre as dores que o filho sofre, a saudade que o filho sente, sem contar as demais preocupações com o emprego, do qual pediu férias após vencer o atestado de acompanhante. Segundo Ramos (2015, p. 111), a mãe é

[...] receptora da tristeza, do sofrimento, do choro, dos gemidos do seu filhinho, abalado por seu estado de saúde e pelas condições de um contexto que the é adverso. Ela também ressentirá desse ambiente, muitas vezes sem a devida acomodação de que necessita e, principalmente, sem a apropriada definição do seu papel com seu filho doente.

Essas e outras questões pairam sobre a vida das mães e familiares que acompanham seus filhos durante as internações, sendo esse um período muito dificil para todos os envolvidos.

Nas palavras de Minecraft sobre frequentar a brinquedoteca, percebeu-se dois tipos

1 Acesso venoso é a inserção de um cateter nos membros utilizado em pacientes que necessitam medicamento e soro. Para mais informações, consultar: https:// portalarquivos2.saude.gov.br/images/pdf/2017/ dezembro/21/10-Cuidados-com-Acesso-Venoso.pdf. 
de privações vividas por ele: a primeira, por se ausentar da escola regular; e a segunda, por ter que se ausentar da brinquedoteca, uma sequência de decepções que poderia causar muita tristeza, mas não foram suficientes para desanimá-lo. Associar a Classe Hospitalar com a brinquedoteca é algo muito positivo nesse contexto, uma vez que se observou a dedicação dos profissionais em trabalhar o lúdico com as crianças e garantir que a brinquedoteca seja um espaço acolhedor, de interação e relações entre mães e crianças. As crianças brincam enquanto aguardam a sua vez para a sala de aula com os professores. Desse modo, a brinquedoteca desempenha um papel fundamental nos hospitais com atendimento pediátrico, trata-se de um espaço destinado a estimular as crianças e seus acompanhantes possibilitando uma melhor qualidade de vida enquanto aguardam a recuperação (ROCHA, 2012).

Pesquisadora: Como você se sente estudando aqui no hospital?

Minecraft: É bom, os professores são bem bonzinhos eles explicam e leem pra mim.

Pesquisadora: Quem escolhe o momento de fazer as aulas?

Minecraft: Eles chegam aqui no quarto e perguntam se eu estou bem, ai eu pego e faço as tarefas.

A relação entre os professores da Classe Hospitalar com os alunos vai além do educar, “o papel dos profissionais passa também por essa ajuda, que tende a reduzir o sofrimento e auxiliar a criança a criar estratégias de enfrentamento" (ROCHA, 2012, p. 127).

Em seguida a esse comentário, Minecraft nos chama para ver o seu desenho, no início da entrevista disse que desenharia um prédio, mas o desenho que ele fez foi de sua própria casa:

Minecraft: Tô desenhando minha casa, eu moro em um condomínio, minha casa é pequena, a gente morava em uma casa grande, mas agora estamos nessa casa pequenininha.

Percebe-se que Minecraft manifesta saudades de sua casa, uma vez que a abordagem gráfica que concebe o desenho é a expressão da criança, considerando isso, a criança desenha o que sente, o que pensa e o que conhece, expressando tudo o que tem dentro de si (PILLAR, 2012).

As experiências de Minecraft com a Classe Hospitalar foram reduzidas ao convívio apenas dos professores, que se dirigiam ao seu leito para propor atividades escolares. A interação com outras crianças não fez parte de sua rotina na maioria dos dias. Entretanto, ficou evidente que $o$ atendimento pedagógico oferecido pela equipe da Classe Hospitalar, mesmo sendo no seu leito, contribuiu para seu amadurecimento emocional diante da condição de internação, bem como o auxílio para o retorno à sua escola de origem.

Figura 2 - Mulher-Maravilha

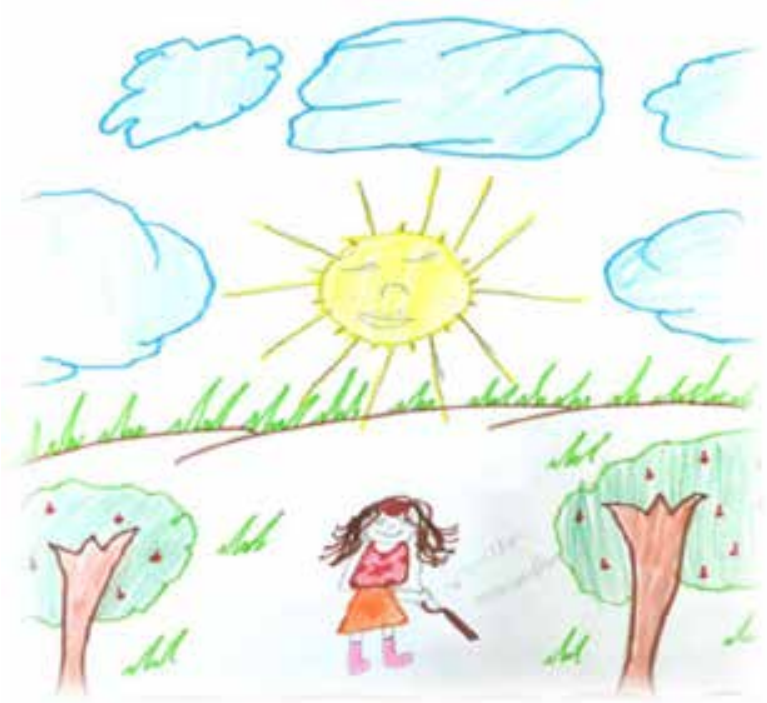

Fonte: construido por: Mulher-Maravilha.

Mulher-Maravilha, uma menina de sete anos de idade, está matriculada no $3^{\circ}$ ano do ensino fundamental I. Mora no interior do estado, na cidade de Nova Alvorada do Sul. O contato com 
a Mulher-Maravilha deu-se uma semana antes da entrevista. Ela estava acompanhada de seu pai. É uma criança muito ativa que faz pinturas, desenhos e atividades em seus livrinhos a maior parte do dia. Muito envolvida com personagens de desenho infantil, logo que foram apresentados os heróis-personagens, ela revelou com empolgação que gostava do Capitão América e da Mulher-Maravilha.

A apresentação dos brinquedos-personagens foi uma maneira de iniciar um diálogo descontraído, dessa forma, conversávamos sobre a preferência de Mulher-Maravilha sobre os bonecos heróis - Homem Aranha, Capitão América, Homem Formiga e Mulher-Maravilha -, sobre qual poder cada um poderia ter, posto isto, nos envolvíamos com as respostas da criança e nas oportunidades que surgiam no decorrer do diálogo, retomávamos as perguntas do roteiro da entrevista.

Mulher-Maravilha estava acomodada no segundo andar, na ala dos queimados. Sobre o acidente ela relata:

Mulher-Maravilha: eu estava brincando com meu primo, daí eu sai correndo atrás dele e a chapa caiu em mim e pegou fogo no meu cabelo e eu sai correndo. Fui para o hospital e depois tive que vir para esse hospital aqui.

O fogo queimou os cabelos, braços e parte das costas da Mulher-Maravilha, sofrendo queimaduras de terceiro grau. Estava internada há 30 dias no Hospital da Santa Casa aguardando cirurgia de enxerto. ${ }^{2}$

Após o diálogo com a Mulher-Maravilha sobre a história dos heróis relatada anterior-

2 Enxerto de pele é um procedimento cirúrgico que envolve a remoção da pele de uma área do corpo e o ato de movê-la ou transplantá-la para uma área diferente do corpo. Essa cirurgia pode ser feita se uma parte do corpo tiver perdido a cobertura protetora da pele devido a queimaduras, ferimentos ou doenças. Toda queimadura profunda (3o ou 2o grau) deve ser tratada com enxertia precoce, para evitar as retrações e sequelas. Nas queimaduras extensas, não há possibilidade de cura da ferida por epitelização (SERRA, 2010). mente, foi perguntado se ela poderia fazer um desenho. Mulher-Maravilha mostrou seu desenho dizendo que começaria a pintá-lo. Notamos que nenhum elogio seria mais significativo para ela do que sua própria satisfação, pois estava muito orgulhosa de seu desenho. Geremias (2010) corrobora ao mencionar que para as crianças, suas produções gráficas têm muito significado, tendo sua própria interpretação, uma configuração concreta do que estava imaginado em sua cabeça. Ao concluir o desenho, a criança o observa, avalia e toma decisões se apaga, corrige, guarda ou faz outro.

Ao comentar seu desenho, Mulher-Maravilha fala como uma heroína, sua imaginação fluiu e produziu seu desenho no contexto dos heróis.

Mulher-Maravilha: Essa aqui é a Mulher-Maravilha, ela tem um poder nos olhos, igual a menina do Thunder Mini (personagem de desenho animado), ela tem raio vermelho...esse raio dá desmaio... esse é o chicote dela...viu as graminhas aqui atrás?

A entonação de sua voz confirmava seu imaginário ao se sentir realmente a personagem que ela se propôs a fazer, visto que, quando a criança desenha ela está representando graficamente características de suas próprias percepções e interpretações (PILLAR, 2012).

Em meio à nossa conversa, nos diz que gosta muito de balé e que sempre dança, ali mesmo no quarto do hospital para se distrair e gosta muito de pular corda também. A criança em condição de internação busca expressar sua linguagem do brincar da maneira que for possivel. Buscando, quando não oferecido, estratégias próprias de enfrentamento de seus medos e angústias, dessa forma, além de possibilitar o desenvolvimento da criança, o brincar no hospital atua como uma espécie de fuga desse contexto, dando-lhe suporte importante para enfrentar a rotina (ROCHA, 2012). Mulher -Maravilha menciona que gosta de brincar na 
escada, quando the deixam passear pelo hospital, ela pede para seu acompanhante levá-la até as escadas: "lá [escadas] é legal, dá até para fazer ginástica e emagrecer".

"O brincar traz em si um sentido tão amplo, onde a dor não tem lugar, que impossibilitar esse espaço é negar a criança seu direito a uma vida plena, é perder o sentido de ser e estar" (ROCHA, 2012, p.125). Brincar atua como um dos remédios para enfrentar esse período de dificuldades e não depende de objetos ou acessórios, pois a criança é criativa suficiente para usar seu corpo como instrumento do brincar. O que nos leva a refletir sobre a condição de Mulher-Maravilha, que mesmo impossibilitada de interagir com as crianças da brinquedoteca, não se deixa abater, buscando alternativas para o brincar dentro de suas possibilidades.

A Classe Hospitalar para Mulher-Maravilha está representada pela professora que a atende no leito, que durante a aula, conversa, brinca, leva brinquedos da brinquedoteca e a escuta. A criança constrói um laço de afinidade e afetividade, e espera ansiosamente por esse momento todos os dias. Entendemos que essa conquista aconteça, não somente pela carência que esse momento ocasiona e por estar longe da família e amigos. Mas, principalmente, pela oportunidade oferecida de participar das aulas ativamente, podendo falar, interromper e opinar no momento que achar necessário.

A Sociologia da Infância, em seus pressupostos, defende que as instituições educativas devem atentar-se para as ações das crianças e considerá-las no processo pedagógico e organizacional, pois o modo como os adultos conceituam as crianças interfere diretamente nessa relação (SOARES, 2015). Sendo assim, há uma grande necessidade de compreender que a criança deve e tem capacidade de participar do processo de ensino e aprendizagem como participante ativa e não apenas como receptora de informações.
Considerando os pressupostos básicos da Sociologia da Infância, em razão de entender a infância como múltipla, plural e diferente, chama atenção a fala de Mulher-Maravilha quando responde que o hospital não precisa de mudanças "Aqui é tudo bom". Durante o diálogo, notou-se que a família da Mulher-Maravilha não dispõe de uma condição financeira confortável. Ao perguntar se estava com saudades de casa, ela respondeu: "Mais ou menos, aqui eu como quase cinco vezes por dia".

Percebemos pela sua fala, bem como observado nos três encontros anteriores, que ela estava de certa forma se sentindo bem ali. A condição social em que vive as crianças entrevistadas não foi foco da pesquisa, mas o caso da Mulher-Maravilha levou a refletir que ela pode ter vivido a experiência da internação com menor intensidade de sofrimento no que se refere à saudade de casa, do que as demais crianças. Pois não é incomum a existência de crianças que não são assistidas por suas famílias e que estão em situação de pobreza e desamparo. E que embora tenham sofrido um acidente ou sofrem de alguma doença, encontram no hospital atenção advinda da classe hospitalar e da equipe de saúde, amizade nas enfermarias, alimentação em horários certos e uma cama confortável, coisas que talvez não existam nas suas rotinas diárias. Por essa perspectiva, Sarmento (2013) corrobora quando enfatiza que as crianças compartilham elementos comuns, mas suas condições de existência concreta interferem, não apenas nas suas condições de existência, mas também na forma como se expressam socialmente.

\section{Reflexões a partir do vivido...}

O tempo vivido durante a pesquisa no campo teórico e empírico provocou muitas reflexões, dentre elas consideramos importante ressaltar o reconhecimento dos direitos das crianças 
por meio da Sociologia da Infância, visto que a Classe Hospitalar atua nesse contexto, assegurando a criança o acesso ao desenvolvimento e educação, mesmo que sua condição de saúde a tenha retirado do convívio e assiduidade da escola regular. $O$ fato de existir um espaço específico para criança no qual desenvolve suas atividades escolares dentro de um hospital é evidência desse reconhecimento de direitos.

A Classe Hospitalar apresenta sem dúvida uma nova proposta de compreender a educação. Observamos que entre adultos e crianças há uma inexistência de hierarquias, o que ficou evidente foi uma relação horizontal, em que a criança é possibilitada de participar, inclusive motivada a isso. Há uma relação de muito respeito e atenção à criança. A Classe Hospitalar resgata o cotidiano pedagógico, perdido pela criança quando internada, dando outro significado ao período de internação.

A experiência da empiria na Classe Hospitalar evidenciou a necessidade de problematizar os direitos da criança no contexto de todas as instituições, pois de acordo com Belloni (2009, p.113), a Sociologia da Infância na contemporaneidade "busca, sobretudo, estudar a infância como categoria válida nas ciências humanas para compreender melhor a situação das crianças reais em nossas sociedades contemporâneas".

Entretanto, na trajetória da pesquisa, foi possivel comprovar que as experiências vividas pelas crianças no período de internação envolvem a dor física e emocional. Fatores que não as impediu de resignificarem o ambiente hospitalar, para torná-lo o mais agradável possivel durante o tratamento de saúde. Ao escutá -las, percebemos que as relações estabelecidas com os pares, adultos e crianças, permitiram construir um cenário à parte, dentro desse grande universo de tensão que é o hospital. 0 hospital foi concebido pelas crianças como um ambiente bom que não necessita de grande mudança, a não ser, melhorar a convivência de crianças acamadas com as demais crianças.

A Classe Hospitalar atua na perspectiva de manter as crianças conectadas com o universo escolar que deixaram ao serem internadas. Os professores exercem uma função que vai muito além do lecionar. Cada aluno recebe um atendimento diferenciado. Desempenham vários papeis no decorrer da rotina, sem contar com o atendimento a família, que vê no professor a possibilidade de cura da dor emocional de seus filhos.

As crianças inseridas, seja qual for o contexto, necessitam ser escutadas e respeitadas. Espera-se que esse estudo possa trazer contribuições significativas para o contexto educacional no que se refere ao atendimento as crianças hospitalizadas, bem como na formação de profissionais que tenham a intenção de fazer parte dessa realidade tão intensa e cheia de significados.

\section{Referências}

ARIÉS, Philippe. História social da criança e da família. 2. ed. Rio de Janeiro: LTC, 1981.

ABRAMOWICZ, Anete; OLIVEIRA, Fabiana de. Sociologia da Infância no Brasil: uma área em construção. Educação (UFSM), v. 35, n. 1, p. 39-52, 2010. Disponível em: <https://periodicos.ufsm.br/index.php/reveducacao/article/view/1602>. Acesso em: 2 jul. 2019.

ABRAMOWICZ, Anete; MORUZZI, Andrea Braga. Infância na contemporaneidade: questões para os estudos sociológicos da infância (Childhood in the contemporary world: questions for the sociological studies of childhood). Crítica Educativa, v. 2, n. 2, p. 25-37, 2016.

BARROS, Alessandra. Notas Sócio Históricas e antropológicas sobre a escolarização em Hospitais. In: S CHILK E, Ana Lúcia, N UN ES, Lauane BaroncelLi, ARO SA, Armando C.(Orgs). Atendimento Escolar Hospitalar: saberes e fazeres. Niterói Ed Intertexto, 2011. p. 19-29. 
BRASIL. Constituição da República Federativa do Brasil. Brasília, 1988.

BRASIL. Estatuto da criança e do adolescente. Lei n. 8060/1990. Brasília, 1990.

BRASIL. Ministério da Educação. Secretaria de Educação Especial. Política Nacional de Educação Especial. Brasília: MEC/SEESP, 1994.

BRASIL. Direitos da Criança e do Adolescente hospitalizados. Resolução 41/95. Conselho Nacional dos Direitos da Criança e do Adolescente. CONANDA. 1995.

BRASIL. Lei n. 9.394, de 20 de dezembro de 1996. Estabelece as Diretrizes e Bases da Educação Nacional. Brasília, 20 dez.1996.

BRASIL. Classe hospitalar e atendimento pedagógico domiciliar: estratégias e orientações para sua implantação e implementação (versão preliminar). Secretaria de Educação Especial do MEC. Brasília: Imprensa Oficial. 2002.

BRASIL. Lei n. 11.104, de 21 de março de 2005. Dispõe sobre a obrigatoriedade de instalação de brinquedotecas nas unidades de saúde que ofereçam atendimento pediátrico em regime de internação. Diário Oficial da União, Brasília, DF, n. 55, seção1, p.1, 22 de março de 2005.

BELLONI, Maria Luiza. 0 que é sociologia da infância. Campinas, SP: Autores Associados, 2009.

CAVALCANTE, Myrian Soares; GUIMARÃES, Valéria Maria Azevedo; ALMEIDA, Synara do Espírito. Pedagogia Hospitalar: histórico, papel e mediação com atividades lúdicas. In: Anais do $\mathbf{8}^{\circ}$ Encontro Internacional de Formação de Professores e $9^{\circ}$ Fórum Permanente de Inovação Educacional, Aracaju, Unit, 2015. Disponivel em: <https://eventos.set.edu.br/index.php/enfope/article/view/1261>. Acesso em: 3 jun. 2019.

CLARA, Maria; PAULA, Sara Rodrigues Vieira de. A experiência de pesquisar com crianças: para além de uma "perguntação". In: Anais do Colóquio Internacional Crianças e Territórios de Infância. Anais... Brasília, UnB, 2018. Disponível em: <https//www.even3. com.br/anais/territoriosdeinfancia/89279-a-experiencia-de-pesquisar-com-criancas--para-alem-de -uma-perguntacao>. Acesso em: 1 ago. 2019.
CORSARO, Willian A. Sociologia da infância. Porto Alegre: Artmed, 2011.

FARIA, Ana Lúcia Goulard de; DEMARTINI, Zeila de Brito Fabri; PRADO, Patrícia Dias (Orgs.). Por uma cultura da infância: metodologia de pesquisa com crianças. 2. ed. Campinas, SP: Autores Associados, 2005.

GEREMIAS, Tania Maria Fiorini. 0 contexto da educação hospitalar nas narrativas de crianças. 2010. Dissertação de Mestrado Universidade Federal de Santa Catarina. Disponivel em: <https://repositorio. ufsc.br/handle/123456789/94101>. Acesso em: 3 ago. 2018.

KUHLMANN Jr., M; FERNANDES, Fabiana Silva. Infância: construção social e histórica. In: VAZ, Alexandre Fernandez; MOMM, Caroline Machado (Orgs.). Educação Infantil e Sociedade. Nova Petrópolis: Nova Harmonia, 2012. p. 21-38

LEITE, Maria Isabel. Espaços de narrativa: onde o eu e o outro marcam o encontro. In: CRUZ, Silvia Helena Vieira (org). A criança fala: a escuta de crianças em pesquisa. São Paulo: Cortez Editora, 2008. p. 118-140.

LIMA, Idalice Ribeiro Silva. Políticas de educação escolar em ambientes hospitalares: em defesa da escola no hospital. Revista Educação e Políticas em Debate, v. 4, n. 1, p. 29-53. 2015.Disponivel em: <http://www.seer.ufu.br/index.php/revistaeducaopoliticas/article/view/31309>. Acesso em: 6 maio 2019.

LÜDKE, Menga. ANDRE, Marli E.D.A.A Pesquisa em educação: abordagens qualitativas.2 ed. Rio de Janeiro: E.P.U., 2014.

NEVES, Flávia. Vivência ou vivencia. Dúvidas de português, 2009. Disponivel em: <https://duvidas.dicio. com.br/vivencia-ou-vivencia/>. Acesso em: 11 jan. 2020.

OLIVEIRA, Tyara Carvalho de. Um breve histórico sobre as classes hospitalares no Brasil e no Mundo. In: Congresso Nacional de Educação, XI., 2013, Curitiba. Anais... Curitiba, PUC, 2013. p. 27685- 27697 Disponivel em: <https://educere.bruc.com.br/ ANAIS2013/pdf/9052_5537.pdf>. Acesso em: 7 jun. 2019. 
PACCO, Aline Ferreira Rodrigues. Panorama das classes hospitalares brasileiras: formação e atuação docente, organização e funcionamento. 2017. 158 f. Dissertação (Mestrado em Educação Especial) Programa de Pós-Graduação em Educação Especial, Universidade Federal de São Carlos - UFSCar. São Carlos-SP. Disponivel em: <https://repositorio.ufscar.br/handle/ufscar/8687>. Acesso em: 1 jul. 2018.

PAULA, Ercília Maria. O ensino fundamental na escola do hospital: espaço da diversidade e cidadania. Educação Unisinos, v. 11, n. 3,2 007. p. 156-164. Disponível em: <http://revistas.unisinos.br/index. php/educacao/article/view/5717>. Acesso em: 13 jun. 2018.

PILLAR, Analice Dutra. Desenho e escrita como sistemas de representação. 2.ed. rev. Ampl. - Porto Alegre: Penso, 2012.

RAMOS, Aidyl M. de Queiroz Perez. O ambiente na vida da criança hospitalizada. Brincando na escola, no hospital, na rua... 3 ed. Rio de Janeiro. Wak Editora. 2015. p. 111-126.

ROCHA, Simone Maria da et al. Narrativas infantis: o que nos contam as crianças de suas experiências no hospital e na classe hospitalar. 2012. $163 \mathrm{f}$. Dissertação (Mestrado em Educação) - Programa de Pós-Graduação em Educação, Universidade Federal do Rio Grande do Norte. Natal, 2012. Disponível em: <https://repositorio.ufrn.br/jspui/handle/123456789/14533>. Acesso em: 1 ago. 2018.

SARMENTO, Manuel Jacinto. Gerações e alteridade: interrogações a partir da sociologia da infância. Educação \& Sociedade, v. 26, n. 91, p. 361-378, 2005. Disponivel em: <https://www.scielo.br/pdf/ es/v26n91/a03v2691.pdf>. Acesso em: 27 out. 2019.

SARMENTO, Manuel Jacinto. Infância contemporânea e educação infantil: uma perspectiva a partir dos direitos da criança. Primeira infância no século XXI: direito das crianças de viver, brincar, explorar e conhecer o mundo, n. 1ä, p. 131-148, 2013. Disponível em: <http://www2.fct.unesp.br/simposios/sociologiainfancia/T4\%20Infancia\%20contemporanea\%20 e\%20educa\%E7\%E3o\%20infantil\%20LIVRO.pdf>. Acesso em: 8 jul. 2019.

SOARES, Natália Fernandes. Os direitos das crianças nas encruzilhadas da proteção e da participação. Zero-a-Seis, v. 7, n. 12, p. 8-18, 2005. Disponível em: < https://periodicos.ufsc.br/index.php/zeroseis/article/view/2100/1780 >. Acesso em: 29 jul. 2019.

SOARES, Natália Fernandes. Pesquisa com crianças: da invisibilidade à participação - com implicações na formação de professores? Pesquisa com crianças e a formação de professores. Curitiba: PUCPRESS. p. 21-44, 2015.

TOMÁS, Catarina. "Participação não tem Idade" Participação das Crianças e Cidadania da Infância. Revista Contexto \& Educação, v. 22, n. 78, p. 45-68, 2007. Disponível em: <https://www.revistas.unijui.edu.br/ index.php/contextoeducacao/article/view/1065>. Acesso em: 15 ago. 2019.

TRUGILHO, Silvia Moreira. Classe hospitalar e a vivência do otimismo trágico: um sentido da escolaridade na vida da criança hospitalizada. 2003. 227 f. Dissertação (Mestrado em Educação) - Pós-Graduação em Educação do Centro Pedagógico, Universidade Federal do Espírito Santo. Vitória, 2003. Disponivel em: <http://www.cerelepe.faced.ufba. $\mathrm{br} /$ arquivos/fotos/137/otimismotragico.pdf>. Acesso em: 1 ago. 2018.

Hildacy Soares da França Montanha é mestre em Educação pela Universidade Católica Dom Bosco (UCDB). Membro do Grupo de Estudos e Pesquisas da Docência na Infância (GEPDI). E-mail: hildacyfranca@gmail.com

Marta Regina Brostolin é doutora em Desenvolvimento Local pela Universidade Complutense de Madri. Realizou estágio pós-doutoral na Universidade do Minho, Braga/Portugal. Professora da Universidade Católica Dom Bosco (UCDB) e do Programa de Pós-Graduação em Educação da UCDB. Líder do Grupo de Estudos e Pesquisas da Docência na Infância (GEPDI). E-mail: brosto@ucdb.br 